\title{
As migrações internas e seu protagonismo contemporâneo nos imaginários urbanos da metrópole de Lima, Peru*
}

Internal migrations and their contemporary protagonism in the urban imaginaries of the metropolis of Lima, Peru

Beatriz Silveira Castro Filgueiras

\begin{abstract}
Resumo
Neste artigo, revisitamos as narrativas construídas sobre as migrações internas no Peru e a explosão urbana de Lima na segunda metade do século XX, de modo a investigar a sua permanência e destacado protagonismo - sobretudo em comparação com outras metrópoles latino-americanas e com os diagnósticos característicos do pensamento urbano regional neste início de século - como elemento central nos discursos e imaginários sobre a metrópole contemporânea. Por um lado, trata-se de compreender as especificidades daqueles processos no caso peruano, no marco mais geral da urbanização latino-americana e dos discursos canônicos que marcaram o seu entendimento. Por outro lado, em diálogo com estudos mais recentes, destaca-se a persistente centralidade do fenômeno migratório nos discursos contemporâneos sobre a cidade e suas dinâmicas socioespaciais.
\end{abstract}

Palavras-chave: imaginários urbanos; migrações internas; América Latina; Lima Metropolitana; Peru.

\begin{abstract}
This paper revisits the narratives about internal migrations in Peru and Lima's urban explosion during the second half of the 20th century, in order to investigate their permanence and protagonism - mainly in comparison to other Latin American cities and to the diagnoses that are characteristic of regional urban thought at the beginning of this century - as a central element of the discourses and imaginaries about the contemporary metropolis. On the one hand, it explores the specificities of the Peruvian case in the broader context of Latin American urbanization and of the canonical discourses that have marked its understanding. On the other hand, in dialog with more recent studies, it highlights the persistent centrality of the migration process in the contemporary discourses about the city and its socio-spatial dynamics.
\end{abstract}

Keywords: urban imaginaries; internal migrations; Latin America; Metropolitan Area of Lima; Peru. 


\section{Aproximação: migrações internas e urbanização na América Latina}

0 fenômeno migratório e a urbanização explosiva durante a segunda metade do século $X X$ foi uma realidade em quase, se não em todos os países latino-americanos. Lefèbvre, em $A$ Revolução Urbana (escrito na década de 1970), vai mais longe ao afirmar que o processo de urbanização, nestas décadas, consistia num fenômeno planetário. 0 crescimento econômico e a industrialização - tornados naquele momento as causas e razões supremas do desenvolvimento - estenderam suas consequências ao conjunto dos territórios, regiões, nações e continentes, evidenciando assim a mundialização do fenômeno urbano. Sendo as causas demográficas, as motivações sociológicas e as vantagens econômicas e políticas da cidade as mesmas, "na China e noutros lugares" (Lefèbvre, 1999, p. 107), a urbanização se revelaria, então, um fato mundial e uma tendência global.

Na América Latina, de um modo geral, esse processo de urbanização caracterizou-se pela natureza cumulativa na localização dos investimentos modernizadores, conduzindo a região, em poucas décadas, ao fenômeno da macrocefalia; isto é, à elevada (e crescente) concentração das atividades econômicas e políticas mais dinâmicas em alguns poucos pontos do território (Santos, 2005). México, Argentina e Chile, para citar apenas alguns exemplos mais emblemáticos, foram países nos quais, assim como o Peru, a urbanização esteve acompanhada por um violento processo de centralização e o desenvolvimento de uma única cidade, a capital, em detrimento do restante do território nacional.

Em função dessa concentração, a explosão demográfica e territorial das grandes cidades latino-americanas deveu-se também a um intenso fluxo migratório de populações vindas do campo ou de outros municípios menores, em busca de melhores condições de vida sonhadas mediante sua incorporação à esfera da economia moderna: "o crescimento desmedido da população urbana criou um círculo vicioso: quanto mais a cidade crescia, mais expectativas criava e, em consequência, atraía mais gente, porque parecia poder absorvê-la" (Romero, 2004, p. 361). Desse modo, a urbanização explosiva, calcada em uma pauta civilizatória e um modelo de desenvolvimento transnacionais, haveria implicado uma ruptura com a base cultural camponesa e a destruição dos vínculos antigos com o espaço, ou seja, o desenraizamento e o rompimento dos mapas tradicionais de territorialização (Latouche, 1996; Ortega, 1986).

Assim, em curto espaço de tempo convencionalmente circunscrito entre as décadas de 1940 e 1980 -, as migrações internas inverteriam o padrão de ocupação do território na maioria dos países da região, agora predominantemente urbano; no Brasil, por exemplo, estima-se que cerca de 40 milhões de pessoas trasladaram-se do campo para as cidades neste período (Fontes, 2008 ). Diante desse crescimento ao mesmo tempo pujante e desmedido, sem precedentes na história da civilização ocidental, emergia uma profunda ambiguidade no entendimento e no tratamento da realidade urbana latino-americana. Expressões como "transbordamento popular" 
(Matos Mar, 2004 ), "enxurrada zoológica", "cidade monstruosa", "cidade de massas" aparecem como traduções do sentimento de caos e desordem e convivem com exaltações ao desenvolvimento urbano da região, expressão ao mesmo tempo de progresso e modernidade (Prevôt Schapira, 2001).

No interior do marco teórico e cultural, definido pelas coordenadas nem sempre concordantes do desenvolvimentismo, do funcional-estruturalismo, da planificação regional e da economia espacial, as cidades da região eram percebidas com uma ambiguidade que oscilava entre a esperança e a desconfiança: como acessos preferenciais de uma corrente de ideias e estilos de vida que libertaria a América Latina das amarras do tradicionalismo e do subdesenvolvimento, incorporando grandes massas de população rural às novas pautas econômicas, sociais e políticas da vida moderna, mas, ao mesmo tempo, como parasitas monstruosos, que sugavam toda a seiva vital do interior de nossos países. (Gorelik, 2005, p. 121)

Entendidas a partir dessa configuração de geografias dualistas - isto é, da divisão estrutural dos territórios nacionais entre 0 "atraso" rural e o "progresso" urbano -, as migrações internas eram vistas como a passagem de sociedades e culturas tradicionais para as cidades modernas, transpondo assim, em poucos dias, "várias épocas de evolução socioeconômica" (Fontes, 2008, p. 26). No movimento de expansão da modernização, moldado pelas relações centro/periferia características da estrutura da sociedade e da economia dos países latino-americanos, o dualismo tradicional/ moderno deveria resolver-se pela universalização do setor modernizador (Gorelik, 2004). A partir da década de 1920, 0 impulso industrializador e os investimentos massivos em educação, em comunicações e na ampliação da rede viária constituíram os principais esforços fomentados pelo Estado para promover a modernização e a integração da economia e do território nacionais.

A transição da sociedade tradicional para a sociedade urbano-industrial supunha mudanças significativas em todas as esferas da vida social. No âmbito político, tal mudança ocorria no sentido da integração das "massas" e seu acesso a direitos políticos e sociais, permitindo a participação mais ampla das camadas populares na cultura industrial-urbana. E a incorporação de grandes setores das classes populares - até então excluídos do projeto político nacional - dependia, sob vários aspectos, da ruptura do isolamento de grandes porções do território e da superação dos limites da comunidade local (Germani, 1965).

Rompendo com aquelas geografias dualistas e seus mapas tradicionais de territorialização (Ortega, 1986) - isto é, com a longa experiência social da dicotomia entre o campo e a cidade, entre o rural e o urbano, como matrizes civilizacionais e modos de vida distintos e opostos -, a "explosão" e a visibilidade das massas urbanas provocariam a desestruturação da sociedade urbana tradicional, aristocrática, oligárquica e excludente. 0 fenômeno migratório e a urbanização explosiva transformariam radicalmente a fisionomia e a morfologia da cidade, sua estrutura e suas dinâmicas socioespaciais. A reorganização do espaço urbano acentuaria o caráter dual da organização social e material das grandes cidades latino-americanas: de um lado, a concentração de infraestrutura, serviços, oportunidades e investimentos 
modernizadores no centro; do outro, a contínua ocupação da periferia urbana, em terrenos de baixo ou nulo valor de mercado, cada vez mais distantes e, via de regra, desprovidos de infraestrutura e bens de consumo coletivos.

Não obstante a marginalização e a inserção precária e conflituosa dos migrantes na cidade, a migração e a urbanização significavam, concretamente, a incorporação de grandes setores da população que até então se encontravam excluídos da maior parte dos aspectos da vida urbano-industrial, do acesso aos direitos sociais e do exercício efetivo dos direitos políticos (Germani, 1965). No plano político, como sujeitos de demandas, os novos habitantes pressionariam pela universalização dos direitos até então restritos às elites urbanas tradicionais, demandando a massificação da infraestrutura e dos serviços urbanos, o acesso à educação, à moradia digna, à saúde, água, transporte, etc. (Martín-Barbero, 1991). No plano da cultura, as migrações promoveriam um processo de integração e fusão cultural, no qual a expansão dos meios de comunicação de massa e o desenvolvimento das indústrias culturais jogariam um papel preponderante, dando lugar à emergência de uma nova cultura popular urbana e à reconstrução dos sentidos do nacional (Martín-Barbero, 2001). Assim, o efeito combinado dos processos de modernização, industrialização e urbanização haveria sido duplo: o surgimento de uma nova cultura popular urbana, "de massas", e, paralelamente, a articulação e redefinição dos princípios políticos de soberania popular, nas quais as noções de cidadania, progresso, modernidade e nacionalidade jogaram um papel fundamental (Nugent, 2007).
Porém, não se trata de afirmar que esse processo de incorporação foi necessariamente "democrático" ou isento de conflitos, ambiguidades e limitações. 0 próprio Germani (ibid.) destacaria, a partir de sua análise do caso argentino, as contradições e assincronias que permearam a integração das massas urbanas no contexto do populismo peronista, bem como sua natureza autoritária e, sob vários aspectos, conservadora. Contudo, afirma o autor, se por um lado as camadas populares não puderam avançar no sentido da transformação estrutural da sociedade argentina, "os resultados mais importantes se devem buscar no reconhecimento dos direitos, e na circunstância fundamental de que desde esse momento as massas populares precisam ser levadas em conta" (Domingues e Maneiro, 2004, pp. 652-653). Assim, podemos afirmar que os setores populares, e os migrantes em particular, atuaram diretamente sobre o processo de modernização e urbanização, tornando-se atores sociais e políticos fundamentais da vida na cidade. A crescente visibilidade das novas massas urbanas se relacionava com a força da sua presença na paisagem, com sua intensa mobilização e organização social e política e a publicização de suas insatisfações e demandas com relação às carências urbanas, numa cidade em rápido e desordenado crescimento (Fontes, 2008).

Apesar do "otimismo" diante da modernização das sociedades latino-americanas, a migração massiva rapidamente seria sentida como um problema, sobretudo pelas elites dirigentes e pelos setores urbanos tradicionais. A explosiva e desordenada urbanização se refletia na saturação dos centros urbanos e no deterioro dos serviços, na emergência e 
na agudização de problemas relacionados à moradia, à especulação imobiliária e à infraestrutura urbana, na visibilidade da pobreza e no aumento da marginalidade e da criminalidade, dos quais era responsabilizada a crescente população migrante (Fontes, ibid.). A cidade seria então retratada como um espaço hostil e sufocante, sujo, degradado, caótico, desordenado e decadente, estigmatizando a população recém-chegada e responsabilizando-a diretamente pelo deterioro das condições urbanas e ambientais. Nesta direção, a migração massiva provocaria, ademais, o descentramento e a desestruturação da cidade, de tal maneira que sua centralidade se bifurcaria entre duas periferias: uma desde a qual os setores populares empreendiam sua "invasão" da urbe ; e outra onde crescentemente se refugiariam as classes médias e altas, de modo a estabelecer sua distância da cidade massificada (Martín-Barbero, 1991).

Por fim, a exclusão e a marginalização de amplos setores da população urbana (neste contexto, predominantemente de origem migrante) não apenas dos circuitos da economia formal, mas do próprio acesso à cidade e seus equipamentos, confeririam à urbanização empreendida pelos setores populares características distintivas, realçadas e reafirmadas constantemente na oposição entre a cidade "formal" e a "informal" e na configuração paradigmática de imagens e imaginários dicotômicos da sociedade e do espaço urbanos, que ainda informa a produção de discursos e diagnósticos em muitas das principais cidades latino-americanas até os dias atuais.

Apenas na década de 1980 esse processo acelerado de urbanização se modificaria. A crise econômica e o esgotamento do padrão de modernização desenvolvimentista, ainda na década de 1970, levariam à reversão das taxas de migração e de crescimento urbano na maioria dos países da região, momento em que também se assiste ao aumento exponencial do desemprego e da pobreza, da informalidade e da violência e à precarização das condições de vida nas principais cidades latino-americanas. Em função dessas transformações, convencionalmente adota-se a "década perdida" de 1980 como o marco temporal para o entendimento da contemporaneidade do subcontinente, momento que marca uma inflexão no fenômeno urbano na região, produzida pela acumulação de diferentes processos - como a democratização e a liberalização econômica, as mudanças significativas nas relações entre cidade e projeto nacional, Estado e planejamento urbano, a crise inflacionária e o esgotamento da temática do desenvolvimento urbano (Prevôt Schapira, 2001) -, abrindo caminho para que os diagnósticos da "crise urbana" se generalizem e se imponham, desde então e com sentidos diversos, como o conteúdo fundamental dos discursos sobre as metrópoles da região (Filgueiras, 2008).

Assim, a década de 1980 marcaria também o começo de um novo ciclo do pensamento social sobre o urbano na América Latina. Além dos diagnósticos acerca da pobreza, da informalidade, da insegurança e da violência fenômenos que, desde então, predominam nos diagnósticos, debates e definições sobre o "caráter" e a dinâmica social das grandes cidades do subcontinente -, a globalização econômica, a reestruturação produtiva e a atualização parcial e estratégica da rede urbana, o aprofundamento da segregação, a fragmentação e a polarização social, a mercadorização da cultura, 
da cidadania e dos mecanismos de proteção social, o enclausuramento do espaço doméstico e a privatização dos espaços públicos (e/ ou sua renovação cenográfica) se tornaram algumas das questões e palavras-chave para a compreensão e a caracterização das metrópoles latino-americanas na contemporaneidade. $E$, nesse novo contexto, inaugurado com o marco da década de 1980 e intensificado nas décadas seguintes, o fenômeno migratório paulatinamente desapareceria da pauta dos estudos urbanos regionais.

No Peru, e particularmente em Lima, embora - como veremos - a reversão das taxas migratórias tenha ocorrido tardiamente em comparação com os demais países da região, surpreendem a centralidade e a força explicativa que as migrações internas ainda desempenham nos discursos e nos imaginários contemporâneos sobre a metrópole limenha, persistindo como elemento central de compreensão da cidade e de suas dinâmicas espaciais e socioculturais. Mesmo os estudos mais recentes, embora insiram a cidade no contexto contemporâneo e dialoguem com ele, em sua maioria seguem tendo como ponto de partida inconteste as transformações decorrentes da migração massiva na segunda metade do século XX. No entanto, antes de discutirmos esse protagonismo, buscando compreender as razões dessa permanência, apresentaremos brevemente as características e especificidades do fenômeno migratório e da explosão urbana no caso peruano e limenho.

\section{Migrações e urbanização em Lima, Peru: cenas de uma "batalha épica"}

Historicamente, o processo de urbanização peruano tende a ser dividido em duas etapas. A primeira abrange o longo período desde a conquista espanhola até a primeira metade do século $X X$, de crescimento urbano moderado aliado à expansão econômica em função dos mercados externos, beneficiando os centros administrativos concentrados no litoral, principalmente o eixo Lima-Callao que, desde a colonização, se consolidava como o espaço urbano mais importante do país. A segunda etapa, por sua vez, abarca a segunda metade do século $X X$, caracterizada pelos esforços de desenvolvimento industrial e integração da economia e do território nacionais, pela urbanização explosiva do país e pelo crescimento acelerado de Lima Metropolitana (Inei, 1996).

Os investimentos feitos para romper com o isolamento dos mercados regionais, particularmente no setor de transportes e comunicação, favoreceram a consolidação do centralismo limenho. Nesse sentido, os processos de expansão econômica e integração territorial promoveriam a consolidação da capital não apenas como centro político e administrativo do país, mas também como ponto nefrálgico da economia nacional, impondo sua hegemonia absoluta sobre o mercado e a economia nacionais, concentrando o poder e as instituições 
do Estado e subordinando sua lógica de desenvolvimento a todas as demais regiões do país. Desse modo, a modernização capitalista da sociedade e da economia peruanas não só reafirmou como expandiu o papel hegemônico de Lima e do litoral peruano, cristalizando a tendência histórica, desde a conquista espanhola, da sua imposição como eixo de gravitação político, socioeconômico e cultural do país, em oposição aos Andes (Franco, 1989). 0 Peru pode ser considerado como cenário de um dos mais intensos processos de centralização do continente, sendo o contrapeso de cidades intermediárias quase nulo (Ávila Molero, 2001). ${ }^{1}$ Devido a este excessivo centralismo, Lima se tornaria o centro distorsionador por excelência da estrutura urbana no Peru, ${ }^{2}$ atingindo um índice de primazia urbana entre os mais altos do mundo (Inei, ibid.). ${ }^{3}$ E, assim, 0 Peru se converteria em um país primordialmente urbano sem, contudo, resolver os problemas seculares de sua estrutura dualista tradicional.

Quase sempre através de imagens de força bélica - como invasão, choque, batalha e conquista - o massivo fenômeno migratório em direção à capital peruana é reiteradamente entendido como um divisor de águas na história da cidade e do país. Nesse período, a população de Lima decuplicou em termos absolutos e, em termos relativos, passou a albergar um terço da população total do país, convertendo o Peru em um país predominantemente urbano (Joseph, 1999).

0 processo de urbanização limenho, resultante do fenômeno migratório ao longo do século $X X$, pode ser dividido em dois momentos. No primeiro, entre a década de 1920 e o final da década de 1960, a migração campesina e a expansão da cidade eram impulsionadas por um "crescimento por desenvolvimento", em função do aumento da atividade mineradora e industrial, fruto da política de substituição de importações, e da atração que gerava a cidade pela expectativa de melhores condições de vida e a possibilidade de incorporação às esferas da economia e do consumo modernos. 0 período entre 1970 e 1990, por sua vez, foi marcado por um "crescimento por crise" (Joseph; Castellanos; Pereyra e Aliaga, 2005), primeiro econômica e depois política, sobretudo em função do conflito interno deflagrado em 1980 que, devido à intensidade da violência no interior do país, contribuiu para a continuidade da migração massiva da população rural e serrana até Lima (Matos Mar, 2004; Portes e Roberts, 2005). ${ }^{4}$

Entre 1950 e 1970, que constituiu o auge das migrações campesinas, a cidade experimentou um vertiginoso processo de expansão territorial; nesse período, de cada 100 migrantes 56 se dirigiam à capital (Joseph, 1999). Nesse momento, as invasões de terrenos, o surgimento e a expansão das barriadas - cada vez mais distantes do centro urbano - se converteriam, então, no fenômeno mais emblemático do processo de urbanização peruano, transformando a paisagem e a morfologia urbana de Lima. Porém, vale ressaltar que não foi somente a população migrante a responsável pela expansão das invasões e urbanizações populares. Neste sentido, Riofrío (1978) cita um censo realizado na barriada pioneira de San Cosme, em 1953 , que constatava que $44 \%$ de seus moradores eram nascidos na capital. "Com efeito, na barriada também havia limenhos: limenhos pobres" (Riofrío, ibid., p. 17 nt. 16 - tradução nossa). De todo modo, os principais protagonistas dessa expansão foram, portanto, os setores 
populares que, diante da inoperância e incapacidade do Estado de absorvê-los e integrá-los à infraestrutura urbana e/ou ao mercado formal de trabalho, buscavam resolver, de modo espontâneo e contestatório, a satisfação de suas necessidades (Matos Mar, ibid.).

Lima constituiria um dos casos mais expressivos, em toda a América Latina, da incontestável presença, crescimento e visibilidade das novas modalidades de habitação popular, fruto das invasões de terrenos e da autoconstrução da moradia - em oposição, por exemplo, aos casos de Buenos Aires, São Paulo ou Santiago, cidades nas quais suas favelas e villas miseria não são vistas com tanta facilidade, muitas vezes despercebidas pelo visitante e mesmo pelo cidadão comum. 0 caso limenho seria também emblemático na região no que tange à expressividade, à capacidade de mobilização e à força organizativa dos novos moradores para a satisfação de suas próprias necessidades em especial de moradia e trabalho - no novo contexto urbano (Romero, 2004).

Nesse processo "espontâneo" de urbanização, que ocorria à margem da ordem oficial, os setores migrantes - e "populares", de um modo geral - criavam novos canais de integração que não guardavam relação com a política ou o projeto urbano-nacional das classes dominantes. Enfrentados com a rigidez da estrutura jurídica, social e política do projeto nacional e com a incapacidade do Estado de atender à explosiva demanda por infraestrutura e serviços urbanos, os migrantes campesinos - através de estratégias coletivas de sobrevivência e de inserção no contexto urbano - rompiam com os limites da legalidade e da institucionalidade vigentes, impondo sua presença e forjando seu lugar na urbe.
0 processo de expansão das barriadas em Lima pode ser dividido em dois momentos. No primeiro, entre 1940 e 1954, as barriadas estavam concentradas no eixo Lima-Callao, localizadas "estrategicamente" em zonas contíguas à área consolidada da cidade. Relativamente pequenas e fragmentadas, continuavam dependentes da área central para o acesso a produtos e serviços e, apesar do contraste que impunham, não constituíam ainda um fenômeno significativo, mas marginal em relação à dinâmica de crescimento da cidade, como um "anexo pobre da cidade tradicional" (Barreda e Ramírez Corzo, 2004, p. 206). Em meados da década de 1950, com a intensificação do processo migratório, as ocupações de terrenos e o crescimento das barriadas ganhariam força e ênfase particulares. Esse segundo momento, entre 1954 e o final dos anos 1980, consistiria no "período clássico" de expansão das barriadas em Lima (ibid.), que começam a localizar-se às margens do tecido urbano consolidado, em terrenos cada vez mais distantes, na maioria das vezes em cerros e areais de baixo ou nulo valor de mercado.

A explosão demográfica e a diversificação das pautas de territorialização urbana, decorrentes do processo migratório, implicaram então uma ruptura histórica na trajetória de Lima, visível na mudança da paisagem, na reestruturação do espaço e da dinâmica urbanas e no novo perfil residencial da cidade (Matos Mar, 2004). Se, na década de 1950, as barriadas representavam ainda $10 \%$ do total da área urbana de Lima, em 1985, 80\% de sua extensão estava ocupada por assentamentos, cortiços e bairros populares (Joseph, 1999). Ao final do século $X X$, mais de $62 \%$ da população de Lima Metropolitana habitava a vasta área que 
os setores populares urbanizaram a partir da década de 1940.

En la práctica, estas invasiones fundaban nuevos polos o núcleos de expansión barrial desde los cuales se ocupan los terrenos adyacentes. Esto hacía que las barriadas continuaran creciendo $y$, con los años y según se fueron rellenando los espacios entre el casco urbano y las barriadas pioneras, formaron lo que ahora son los conos de la ciudad. Es también a partir de este periodo que podemos hablar de ciudad popular como un fenómeno trascendente y definitorio para la urbe. ( Barreda e Ramírez Corzo, 2004, p. 206 - grifo nosso $)^{5}$

No entanto, de modo a evitar reduzir o entendimento do crescimento urbano limenho apenas ao fenômeno das barriadas, é necessário compreender, como parte de um único processo de expansão, o crescimento tanto da cidade "formal" como da cidade "informal". "A urbanização de tipo convencional, assim como a barriada e o cortiço são três modalidades de desenvolvimento das áreas residenciais que se dão simultaneamente" (Riofrío, 1978, p. 6 - tradução nossa). No que tange à atuação do Estado, durante o período de maior crescimento - logo, de maior pressão e demanda habitacional -, se perfilaria claramente uma política de "duas caras", tanto na questão da moradia quanto no provimento de infraestrutura e serviços urbanos: por um lado, a lógica da acumulação e do desenvolvimento capitalista do mercado, dos grandes empreendimentos privados e da especulação do solo urbano; por outro, uma política de "deixar fazer" com relação às barriadas, revestida com a "demagogia da autoajuda" (Riofrío, ibid., p. 38).
A partir da década de 1960, o Estado peruano atuaria em distintas frentes em sua política habitacional. Por um lado, programas de erradicação de barriadas e reassentamento de populações, em particular aquelas que estivessem em terrenos de interesse imobiliário e/ ou estatal, nos eixos já consolidados de expansão da cidade. Por outro lado, a fomentação de programas habitacionais que, no entanto, atendiam primordialmente aos setores médios, aos quais foram destinados $91 \%$ dos investimentos em moradia nesse período. Assim, por omissão, repressão ou por políticas habitacionais que não eram destinadas aos setores mais carentes e vulneráveis, o Estado - em sua ineficiência - terminou se transformando, ele mesmo, em um agente fundador de novas barriadas, cada vez mais distantes do tecido urbano, como foi o caso emblemático do distrito de Villa El Salvador (ibid.). ${ }^{6}$

Perante a impossibilidade e/ou a falta de vontade política do Estado de fazer frente às vertiginosas transformações, a modalidade predominante de acesso ao solo foi a invasão e a ocupação dos areais e áreas agrícolas na periferia da cidade. Devido à forte mobilização e articulação política dos setores populares, o Estado terminou por legitimar as invasões como modalidade de acesso ao solo e à moradia, "sempre e quando [...] não afetassem os interesses do capital imobiliário" (Barreda e Ramírez Corzo, 2004, p. 208 - tradução nossa), através da legalização dos terrenos uma vez já consolidada a ocupação e iniciada - pelos próprios moradores - a (lenta) urbanização da área. Da ocupação e loteamento dos terrenos à construção de cabanas de esteira, a moradia será, para esses setores, um projeto familiar em busca de 
sua melhoria e sua progressiva construção em tijolos e cimento. Por outro lado, os esforços de legalização e habilitação urbana foram comumente um projeto coletivo, pelo menos até a década de 1970, assumindo o custo de construção da cidade através do trabalho comunitário (Barreda e Ramírez Corzo, 2004). ${ }^{7}$

As três grandes áreas onde se estabeleceram estas "barriadas periféricas" absorveram a maior parte da população recém-chegada à cidade durante a segunda metade do século XX. Num processo acelerado de crescimento e urbanização, essas áreas se converteram nos eixos principais de expansão da cidade, porém em sentido inverso - de fora para dentro -, ocupando os espaços intersticiais que as separavam da zona consolidada da cidade e levando à conformação dos Cones de Lima (Cone Norte, Cone Leste e Cone Sul) que constituem, hoje, as áreas de crescimento mais dinâmico da metrópole limenha.

Por sua vez, o centro de Lima passava também por intensas transformações, numa espécie de gentrificação às avessas: com seus "cavalos de tróia", a massa migrante, que havia tomado os cerros da capital peruana, finalmente "conquistaria" seu centro físico e simbólico (Golte e Adams, 1987). Com a ocupação do centro pelos setores populares, denunciava-se seu acelerado processo de deterioro físico e de "degradação social", refletidos na fisionomia e nos hábitos de seus novos usuários, no congestionamento, no encortiçamento e na explosão da economia informal e do comércio ambulante. Finalmente, as classes média e alta consumavam seu abandono (residencial) da área central e buscavam novas estratégias de isolamento, gerando maior segmentação e fragmentação urbanas e produzindo certo desmembramento da cidade (Sachaedel, 1982).

Em função dessa tendência centrífuga e da contínua urbanização das zonas periféricas, Lima se convertia em uma metrópole policêntrica. Não obstante, apesar do crescimento e consolidação de novas "centralidades periféricas" nos eixos de expansão da cidade, o centro limenho conservaria sua força na dinâmica urbana, nos discursos e no imaginário da cidade, disputado ora como o centro "perdido" pela elite criolla ora como o centro "conquistado" pela população migrante. Nesse processo, a própria noção de centro se transfiguraria, acompanhando a expansão urbana e as mudanças de escala implicadas na conformação do território metropolitano, tornando-se referente do "centro expandido" da metrópole, também denominado "Lima Centro" - e as variantes "Lima Moderna", "Lima Consolidada", ou apenas "Lima" em oposição à "Nova Lima" - que inclui em sua definição, além do centro histórico, outros 15 distritos de urbanização tradicional. ${ }^{8}$ Centro que se reafirmaria, concreta e simbolicamente, como o núcleo articulador da cidade em seu conjunto, definidor e difusor das pautas urbanas, políticas, econômicas, sociais e culturais hegemônicas o principal referente normativo da metrópole limenha, a partir do qual se estabelecem as distinções entre a cidade "formal" e a "informal", a "moderna" e a "popular".

Enfrentavam-se simbolicamente, então, duas "Limas": a Lima invadida - as áreas de urbanização "tradicional", resultantes da modernização aristocrática e do projeto nacional criollo na virada e início do século XX - e a Lima invasora, isto é, a "Nova Lima" forjada 
pelos setores populares e pela população migrante. E, nesta disputa, evidenciava-se a natureza essencialmente conflitiva da acomodação desses migrantes na cidade e sua crescente marginalização, tornando visíveis e patentes as profundas desigualdades econômicas, sociais, culturais e raciais presentes na sociedade peruana, impressas no espaço urbano e sensíveis na precariedade de condições de vida de seus novos habitantes.

No entanto, se, do ponto de vista oligárquico, a migração massiva e a explosão urbana da capital peruana eram percebidas como um processo de decomposição e deterioro, por outro lado, a migração massiva e a urbanização empreendida pelos setores populares não deixaram de instituir, a seu modo, um processo singular de modernização. Nesse sentido, 0 fenômeno migratório tendeu a ser compreendido como processo fundante de uma outra modernidade peruana (Franco, 1991), como a democratização social da metrópole limenha e o surgimento de uma nova - e agora "autêntica" - identidade nacional-popular. Impondo sua presença, a massa migrante nacionalizava a capital peruana e a reconstruía democraticamente: ao "conquistar" a cidade hostil e historicamente alheia ao "Peru real", os migrantes forjaram uma "Nova Lima", em cujo seio emergiria "uma nova peruanidade" (Degregori; Blondet e Lynch, 1986).

Se, até então, as dicotomias étnicas e socioculturais da sociedade peruana e seus mapas tradicionais de territorialização coincidiam em grande medida com a divisão geográfica do país entre a costa e os Andes, a migração massiva trasladaria o locus do andino do campo para o espaço urbano limenho. Dessa forma, o processo migratório haveria implicado, então, a reinterpretação da "geografia da identidade" peruana (Cánepa, 2007), dando lugar a uma narrativa - concebida de maneira épica - que incluía o deslocamento, entendido como a apropriação concreta e simbólica do território da nação, como figura retórica para a construção identitária e a imaginação nacional: a partir de seu encontro na capital, migrantes de todas as regiões do país articulariam planos de convergência, fortalecendo a conformação de um tecido "verdadeiramente" nacional e dessa nova e "autêntica" identidade nacional-popular (Degregori; Blondet e Lynch, ibid.).

Paradoxalmente, essa narrativa do "nacional-popular" - enunciada, em Lima, para referir-se tanto à presença na capital de migrantes andinos e seus descendentes, como aos processos políticos, econômicos e culturais decorrentes dela - serviria não apenas à homogeneização e à regulação discursiva de um processo muito mais complexo, heterogêneo e, por vezes, contraditório, como também contribuiria à reafirmação da hegemonia limenha sobre 0 resto do país. Isto é, ao mesmo tempo em que a migração era destacada como o mecanismo central da transformação cultural e política do país no sentido da sua democratização, sua configuração discursiva contribuía para a reprodução de uma geografia de identidade centralista (Cánepa, 2007).

Dessa forma, no marco das profundas transformações ocorridas desde meados do século XX, a centralidade e a hegemonia de Lima no contexto nacional peruano se atualizariam, então, com um sentido completamente distinto. 0 centralismo limenho passaria a se justificar não mais por ser o centro definidor e irradiador do projeto criollo de uma nação moderna, mas por conter em si - e, logo, ser representativa 
de toda a diversidade étnica e cultural do país. Nesse momento, o centralismo de Lima se reinventava encontrando, assim, sua legitimação "popular" e Lima, mais peruana que nunca, se atualizaria como metáfora e síntese simbólica e imagética desse novo Peru e de sua identidade nacional.

Contudo, a profunda ambiguidade no tratamento da população migrante - ora como os sujeitos heróicos da "nacionalização" da capital peruana, ora como expressão da pobreza, da desordem e da marginalidade - expunha a polarização da sociedade, revelando a recriação e atualização, no espaço urbano, das seculares representações dualistas do universo cultural peruano. "Da dualidade do país passou-se a falar da dualidade na cidade [...]. Do étnico ao popular, da diferença à desigualdade, da oposição ao conflito, o esquema dual permaneceu" (Montoya Uriarte, 2002, p. 42 tradução nossa). De todo modo, o que constituía uma realidade heterogênea e contraditória tendeu a ser definida através de discursos e narrativas que enfatizavam a homogeneidade das experiências urbanas através da concepção dicotômica das novas dinâmicas espaciais e socioculturais da metrópole, sintetizadas no "choque" e na "batalha" entre mundos inconciliáveis e na oposição entre a "Lima" tradicional, senhorial e criolla e a "Nova Lima", de origem migrante, andina e popular.

Nesse sentido, a migração massiva e a nova realidade urbana decorrente dela não apenas implicaram a transformação radical do panorama físico e social da cidade, mas poriam em cheque a própria definição do "limenho" (Franco, 1989); referente identitário que, ao ser fixado como um estereótipo que já não guardava relação com o perfil e a dinâmica sociocultural da cidade, pouco significado ou relevância teria para seus novos habitantes. Nessa direção, uma das consequências mais marcantes, derivada da convulsão social e cultural decorrentes da migração massiva, seria um duplo processo de rejeição da cidade e de sua identidade cultural. Por um lado, os setores urbanos "tradicionais" mitificavam a identidade limenha criolla que se extinguia com a "invasão" campesina, mobilizando nostalgicamente uma identidade que não apenas constituiria expressão da sua rejeição às novas configurações espaciais e socioculturais da cidade, mas que serviria também como marcador de distinções e hierarquias sociais no novo contexto urbano (Montoya Uriarte, ibid.). Por sua vez, aqueles recém-chegados à capital não se identificariam com essa identidade urbana limenha nem com a cidade que tal identidade evocava e que, por definição, os excluía. Em oposição a esta "limenhidade" na qual não tinham acoIhida, os novos habitantes da cidade afirmariam sua presença e sua singularidade cultural identificando-se não como limenhos, mas como provincianos, como habitantes de algum distrito popular da cidade (nas amplas áreas invadidas e urbanizadas por eles), cholos ${ }^{9}$ ou, simplesmente, peruanos (Degregori; Blondet e Lynch, 1986).

Certamente, a "cholificação" de Lima (Quijano, 1980) não deve ser entendida apenas como um processo de enfrentamento e oposição, mas também como o encontro e a articulação entre diversas matrizes e orientações culturais, de populações oriundas de todas as regiões do país que converteriam a capital na "cidade de todos os sangues do Peru". Não obstante, como discurso identitário, o "limenho" como sinônimo do criollo, ainda que 
deslocado no tempo e no espaço pelo impacto da migração andina, persistiria como um importante referente ideológico que recria e reproduz, no espaço urbano, as fraturas e dualidades constitutivas do imaginário e dos discursos acerca da identidade nacional.

Finalmente, com a deflagração do conflito interno, entre 1980 e início da década de 1990, o crescimento urbano de Lima cobraria outro sentido. As barriadas, como unidade urbana de expansão, foram seriamente afetadas pela desarticulação, intimidação ou pelo assassinato das organizações e lideranças comunitárias que, até então, caracterizavam a constituição e a urbanização desses espaços, alterando seus ritmos de reprodução e adaptação. Por outro lado, surgiam novos espaços urbanos na extrema periferia da cidade, nos quais se instalaram populações inteiras de refugiados pela violência interna e que, devido à crise generalizada vivida pelo país nesse período, se trasladavam ao contexto urbano em condições de pobreza, precariedade e vulnerabilidade extremas, muito mais agudas que aquelas enfrentadas pelos migrantes do período "clássico" (Matos Mar, 2004). Ademais, a crescente estigmatização dos territórios populares, sobretudo os distritos periféricos da cidade - fruto da identificação desses espaços e de sua população com a zona de conflito e com o conflito em si, marcados por um forte componente étnico-cultural - aprofundariam as fraturas da sociedade peruana e a tendência generalizada ao isolamento, ao receio e à hostilidade (Rodríguez Robles, 1997).

Nesse período, já se constatava a reversão das taxas de migração e de crescimento urbano explosivo na maioria dos países da América Latina e, nesse contexto, a paulatina retração dos discursos sobre o fenômeno migratório como um processo definidor da cena e da dinâmica urbanas nas grandes metrópoles da região. Na contramão dessas tendências regionais, a continuidade do processo migratório em direção a Lima até o início da década de 1990 talvez tenha contribuído, num primeiro momento, para que as migrações internas permanecessem como elemento explicativo central das dinâmicas espaciais e sociais da metrópole. No entanto, passadas mais de duas décadas, as migrações internas ainda preservam um destacado protagonismo nos diagnósticos, discursos e nos imaginários contemporâneos da metrópole limenha e as razões e sentidos dessa permanência devem ser, portanto, buscadas em outra parte.

\section{Lima contemporânea e os sentidos do pertencimento à metrópole: novos processos, mesmos discursos?}

Após as décadas intensas e traumáticas da crise generalizada que afligiu o país nas últimas décadas do século $X X$, Lima se consolidava como um território metropolitano que alcançaria, no início do ano 2000, os 7,5 milhões de habitantes e uma vasta área conurbada abrangendo, além dos 43 distritos que a compõem "formalmente", a Província Constitucional de Callao. ${ }^{10} \mathrm{~A}$ estabilização e a retomada do crescimento econômico - em índices que, na última década, seriam os mais elevados de toda a América Latina (Ludeña Urquizo, 2009) -, a reversão das taxas migratórias e de crescimento urbano explosivo, a reabertura democrática 
após quase uma década de um regime autoritário, ${ }^{11}$ os desafios da reconciliação nacional e a reinserção econômica e cultural do país nos fluxos do capitalismo globalizado informariam a entrada da capital peruana no novo século.

0 processo de transformação contemporâneo do espaço urbano limenho teve início em meados da década de 1990, com o fim do conflito interno, o início da chamada "pacificação nacional" e a aplicação de um modelo radical de reativação econômica (Chion, 2009). No contexto do choque neoliberal promovido pelo governo de Fujimori, Lima rompia seu isolamento da economia global mediante incentivos ao investimento estrangeiro, concessões e privatizações de empresas públicas, liberalização do comércio exterior e a manipulação do câmbio e das taxas de juros para garantir a atração de capitais (Romero Reyes, 2004). Além dos setores financeiro, de energia, transporte e telecomunicações, foram favorecidos o setor comercial e de serviços e as grandes empresas nacionais e transnacionais, entre as quais se destacam as indústrias extrativistas e o setor da construção civil que, desde então, promoverá um boom especulativo e imobiliário de grande impacto na paisagem e na estrutura urbana limenha (Ludeña Urquizo, 2009). ${ }^{12}$

Na última década, as orientações impostas, fundamentalmente, pela globalização econômica e pela adequação diferenciada da atuação e estrutura do Estado, têm um forte impacto no conjunto da área metropolitana de Lima e Callao, produzindo novas diferenciações pela localização desigual dos componentes da nova economia. Assim, as novas diretrizes que orientam a produção do espaço urbano na contemporaneidade - em Lima como nas principais cidades latino-americanas - estão transformando de modo acelerado a paisagem da metrópole limenha, que experimenta um crescimento sem industrialização baseado na expansão de grandes centros comerciais, nas grandes obras de mobilidade, na revitalização cenográfica do patrimônio histórico e cultural, ${ }^{13}$ no desenvolvimento de serviços e estrutura vinculados à economia de serviços e do turismo e na expansão da intermediação especulativa e financeira que alcança também, cada vez mais, os Cones de Lima (Romero Reyes, ibid.).

Por um lado, vê-se a proliferação de novos projetos de modernização urbana vinculados à nova hegemonia dos fluxos globais que, incidindo de maneira desigual sobre o território metropolitano, redefinem as relações entre o centro e a periferia limenhos, favorecendo a emergência de uma nova hierarquia espacial metropolitana (Chion, 2009). Em Lima, constitui expressão dessa nova orientação no planejamento urbano a consolidação de um "centro triangular", que define hoje os espaços e os fluxos hegemônicos da economia metropolitana e nacional. Esse centro triangular está conformado por polos de funções especializadas, conectados por vias de ampla circulação, cujos vértices são: (1) o Cercado de Lima - o centro histórico, político e econômico que concentra as sedes do governo central, do legislativo e do poder judicial, ministérios e banco central; (2) o centro comercial e industrial de Callao, onde estão o porto e o aeroporto mais importantes do país; (3) o centro financeiro e comercial dos distritos de San Isidro e Miraflores, que concentra os fluxos de turismo e de negócios, as instituições financeiras e empresas privadas, companhias de seguros e grandes centros comerciais (Romero Reyes, 2004). Completa esse reordenamento seletivo a criação de um novo 
eixo exclusivo (leste-oeste), com a construção de vias expressas e centros comerciais de luxo que conectam esses distritos ao aeroporto de Callao, ao centro da cidade e às zonas residenciais de alta renda, da qual o distrito de La Molina constitui o exemplo mais emblemático (Ludeña Urquizo, 2009).

Por outro lado, em grande medida à margem dos fluxos hegemônicos desse renovado dinamismo, Lima ingressa num momento de consolidação de seu espaço urbano e de novos processos de diferenciação social que transformam o fenômeno e os rostos da pobreza urbana nas vastas áreas urbanizadas pelos setores populares ao longo da segunda metade do século XX (Cabrera, 2009; Riofrío, 2009). Passado o período de crescimento urbano explosivo, muitas barriadas, sobretudo as zonas de ocupação mais antiga, cresceram e se urbanizaram, convertendo-se em bairros periféricos consolidados, ainda que não necessariamente tenham superado a pobreza que os caracteriza. A consolidação desse espaço urbano "popular" se evidencia não apenas na infraestrutura que agora supre muitas dessas áreas, mas também na verticalização, densificação e complexificação dos usos do solo, em um dinâmico mercado imobiliário informal (Riofrío, ibid.), no surgimento de uma nova classe média emergente, na construção e consolidação de novos centros comerciais e de serviços que, pelo seu dinamismo, despontam e se configuram como as novas centralidades "periféricas" da metrópole de Lima.

A consolidação e o crescimento econômico dessas novas centralidades nos Cones de Lima - que é também desigual e produtora de novas desigualdades - se apoiam principalmente na expansão e diversificação do setor de comércio e serviços, sobretudo pequenas e médias empresas de caráter familiar e, em sua grande maioria, informais. ${ }^{14}$ Animados e atraídos pela consolidação e efervescência dos distritos populares limenhos, na última década crescem os investimentos em grandes empreendimentos comerciais nos Cones de Lima, em função desse dinamismo urbano e econômico, mas também pela "constatação" de uma demanda de mercado insatisfeita, isto é, de uma grande parte da população limenha que ainda anseia por consumo e "modernidade". Albergando quase dois terços da população metropolitana, "os 'cones' foram se constituindo nas economias emergentes da metrópole e não é gratuito que as grandes empresas comerciais e cadeias de supermercados tenham visto aí potenciais mercados de consumo" (Arroyo e Romero, 2008, p. 111 - tradução nossa). Nos Cones de Lima, cuja história de urbanização está associada à mobilização e organização popular para a habilitação comunitária do espaço urbano e cujo crescimento se deve ao dinamismo alcançado por uma economia basicamente informal e familiar, seu impacto não deve ser menosprezado - sobretudo se consideramos que sua construção se dá verticalmente em função de agentes externos e privados, em detrimento da melhoria em infraestrutura e serviços que ainda continua a depender, em grande medida, dos recursos e da atuação dos próprios moradores. ${ }^{15}$

Essas novas tendências na organização do território metropolitano - sua atualização parcial e seletiva, o surgimento de novas centralidades e a proliferação de tipologias/arquiteturas fragmentadoras do tecido urbano têm por consequência, ademais, o aumento da polarização social e espacial, estimuladas não 
apenas pelos renovados processos de diferenciação intra-urbana - entre bairros da cidade, entre o(s) centro(s) e a(s) periferia(s) -, mas também induzem e promovem novos processos de diferenciação social no interior da periferia urbana. Nesse sentido, observa-se o aprofundamento da diferenciação entre a pobreza e a pobreza extrema (Riofrío, 2004) que se evidencia nas condições e possibilidades diferenciadas de ocupação e apropriação do espaço urbano e de inserção social. Ocupando os "espaços opacos" da metrópole globalizada (Santos, 2005), emergem os rostos de uma "nova pobreza urbana", marcada pela experiência de uma marginalização radical e pela hiperperiferização da moradia que impedem a reprodução de estratégias tradicionais de sobrevivência e dificultam a organização social e política, tornando ainda mais precárias das condições urbanas de vida (Ribeiro, 2009).

Assim, embora o atual dinamismo urbano de Lima esteja nas áreas já ocupadas da metrópole, continuam a surgir novos bairros e assentamentos na extrema periferia, onde não apenas a construção da moradia, mas também a instalação de serviços e equipamentos urbanos resulta ainda mais problemática (Riofrío, 2004). Apenas nos distritos do Cone Sul de Lima foi estimada, nas últimas duas décadas, a demarcação de mais de $\mathbf{4 0}$ mil lotes nos novos bairros da extrema pobreza, albergando cerca de meio milhão de habitantes (Riofrío, 2010a). Nessas áreas, onde transparecem o aprofundamento da polarização e da segregação socioespacial, "mecanismos de reprodução ampliada do isolamento" contribuem de forma combinada para sua perpetuação (Kaztman e Ribeiro, 2008), definindo os (novos) ganhadores e perdedores da cena urbana contemporânea.
Por sua vez, apesar das transformações ocorridas na última década no sentido de uma maior dispersão dos espaços de referência da metrópole, o centro de Lima não apenas conserva grande parte de suas antigas funções concentrando quase a totalidade das instituições públicas e dos empregos formais, a infraestrutura e os serviços mais modernos -, como também se redefine, adequando-se às novas dinâmicas metropolitanas e às novas demandas introduzidas pela globalização econômica e cultural. Nesse sentido, o centro histórico, particularmente, é objeto de intensas reformas no sentido de sua revitalização urbana e cultural e do afiançamento de uma renovada identidade local (Vega Centeno, 2009). Em suas diferentes manifestações, a parcialidade evidente na revitalização do centro histórico introduz novas diferenciações socioespaciais e aprofunda antigas, transfigurando a vida de relações que o anima, impondo usos e códigos de comportamento cada vez mais restritivos - seja por mecanismos de vigilância e/ ou regulados pelo consumo individual -, que implicam seu alisamento e sua banalização como cenário para o entretenimento fácil, a contemplação fugaz e o consumo sempre renovado (Ribeiro, 2004).

No entanto, o centro de Lima está longe de constituir meramente expressão dos novos impulsos e necessidades dominantes. Apesar dos esforços recentes para a atualização "estratégica" do centro - agora em busca da atração de investimentos, turistas e visibilidade global -, o centro mantém ainda fortes elementos simbólicos e identitários para os habitantes da metrópole (Vega Centeno, ibid.). Moradia, educação, trabalho e oportunidades de renda, mobilizações políticas, intervenções artísticas, 
encontros, lazer, práticas e usos do espaço que, à margem e a despeito dos projetos e intenções hegemônicos, estabelecem outra cartografia social e cultural do centro histórico limenho.

Em todo caso, o centro de Lima continua, portanto, condicionando os fluxos e as dinâmicas metropolitanas e, neste processo, se atualiza e se reafirma como o principal referente normativo da metrópole, a partir do qual se estabelece a oposição entre a cidade "formal" e a "informal", a "invadida" e a "invasora", a "moderna" e a "popular". Porém, ao atualizar-se também como o centro "invadido" e "conquistado" por seus novos habitantes, constitui um espaço em aberta disputa: a referência mais emblemática a partir da qual, ou em oposição a qual, se elaboram os discursos, os imaginários e os sentidos da diferença e do pertencimento na metrópole limenha.

Como vimos, desde meados do século $X X$, com as migrações massivas e o crescimento explosivo de Lima, a estruturação urbana e as representações da cidade se articulariam fundamentalmente pela coexistência, diferenciação e antagonismo entre dois "mundos" e modos distintos de produção da cidade: 0 espaço "formal" e "moderno", habitado pelos setores urbanos tradicionais e consagrado pelas instituições oficiais; e o "informal", de origem migrante e popular e que carrega 0 signo da precariedade e da "espontaneidade" (Cabrera e Villaseca, 2007). Nas últimas décadas, o dinamismo econômico e cultural dos Cones de Lima, a consolidação de novas centralidades periféricas, a complexificação dos fluxos intraurbanos e a mudança no comportamento das gerações mais jovens - além da mobilidade oferecida por um sistema de transporte que, apesar de extremamente precário, é relativamente acessível (Joseph; Castellanos; Pereyra e Aliaga, 2005) - favorecem e apontam para novas formas de apropriação do espaço urbano metropolitano. Os circuitos não apenas se tornam mais intensos e complexos, mas também multidirecionais. No entanto, persiste a percepção dicotômica entre os espaços representativos da metrópole limenha sintetizados, sobretudo, naquela oposição entre "Lima" e a "Nova Lima"; distinção que, como vimos, se associa precisamente com as migrações massivas em direção à capital e seu crescimento explosivo.

Nesse sentido, embora o contexto contemporâneo da metrópole já não seja aquele das migrações massivas e da explosão urbana, permanece o imaginário - inscrito nesta oposição - do "choque cultural" e da cisão entre os "limenhos" e os "migrantes" que, mesmo vivendo há décadas na capital, dificilmente se identificam com ela. Desencontro e dualidade que se reproduzem nas gerações nascidas em Lima e que, até os dias de hoje, continuam a ser nomeadas "filhos/descendentes de migrantes", "migrantes de segunda, terceira ou quarta geração", ou apenas "novos limenhos". Adjetivos que servem para a manutenção das distinções e hierarquias sociais e para a reprodução indefinida de estigmas e estereótipos que perpetuam a oposição entre os setores criollos tradicionais e os habitantes desta "Nova Lima", recriando as rígidas fronteiras entre o limenho "puro" e o "invasor". Nesse embate, não é raro encontrar quem afirme - com certa ironia - que, atualmente, os "limenhos" são minoria, quase uma "espécie em extinção" na capital peruana.

Para as gerações mais jovens, a percepção de Lima como parte de sua origem e de sua 
identidade aparece, muitas vezes, como uma contingência, uma casualidade quase formal. Por outro lado, ressignificam e reconstroem seus laços com outros lugares de origem - seus próprios, de seus pais ou avós -, nos quais a memória e a cultura jogam um papel fundamental (Jacinto Pazos, 2007). Transitando entre âmbitos geográficos e realidades sociais completamente distintas - entre memória ancestral, a herança cultural, a contingência do nascimento e a vivência da metrópole -, a identidade dos "novos limenhos" carrega a marca dessa dualidade conflitiva, como evidencia o depoimento de um jovem (sem identificação), citado por Ríos Burga (2006, p. 311 - grifo nosso):

Me considero limeño, pues nací en Lima, pero mis padres nacieron en provincias y por ende sus padres también, lo cual también me hace en parte de la provincia de donde ellos vienen, pero también me hace limeño legalmente hablando porque la partida de nacimiento explica mi lugar de nacimiento, en conclusión soy limeño y a la vez soy provinciano. ${ }^{16}$

Nesse sentido, argumentamos que, nos discursos e nos imaginários contemporâneos sobre a cidade, "Lima" constitui um referente anacrônico na medida em que seus sentidos e conteúdos permanecem cristalizados em sua imagem e tradição criollas, circunscritas a uma região específica da cidade, ameaçadas e/ ou perdidas pela invasão migrante. Ademais, "Lima" se revela também um referente excludente na medida em que serve justamente para a atualização e/ou a denúncia de sua hegemonia e centralismo, reafirmando as fraturas e polarizações que, historicamente, ela mesma institui: aquela entre o mundo criollo e o mundo andino, entre a capital e o "resto do país".
Dualidade que não apenas permanece vigente no plano nacional, mas que se inscreve no espaço, no cotidiano e nos imaginários da metrópole e cuja expressão mais visível e contundente é precisamente a reafirmação constante da existência de duas cidades: "Lima" e "Nova Lima", ou qualquer de suas variantes, a "formal" e a "informal", a "moderna" e a "popular".

Dualidade que se impõe, finalmente, como o principal eixo articulador das experiências e dos sentidos da diferença que traçam e, ao mesmo tempo, tencionam as linhas do pertencimento e da exclusão nos imaginários contemporâneos da metrópole de Lima. Essa polarização, no entanto, não reflete meramente uma divisão convencional entre classes nem pode ser reduzida à expressão de desigualdades socioeconômicas ou espaciais; tratam-se, sobretudo, de experiências, sensibilidades e estereotipias que, profundamente enraizadas no sentido comum e inscritas no espaço urbano da metrópole, não são de fácil desconstrução e que tendem a reproduzir-se na medida em que as condições objetivas e subjetivas que sustentam sua vigência permanecerem inalteradas.

Tanto em certo sentido comum como na maior parte da literatura especializada sobre a cidade - inclusive estudos mais recentes -, Lima continua sendo definida como uma cidade senhorial e criolla, invadida por migrantes de origem rural que ocupam terrenos e impregnam a urbe com presenças e manifestações culturais de colorido andino. $\mathrm{E}$, nesse quadro, o fenômeno das migrações internas permanece, em grande medida, como o elemento explicativo inconteste de sua estrutura e dinâmica urbanas, da sua vida social, da totalidade dos problemas e desafios que enfrenta a metrópole. No entanto, essa descrição claramente 
já não corresponde ao contexto econômico e político metropolitano, nem à sua realidade urbana e social, cujas dinâmicas respondem agora a novos determinantes, sendo $75 \%$ de seus habitantes nascidos na capital, jovens em sua maioria (Riofrío, 2009 ). Se quisermos compreender o contexto contemporâneo da sociedade e da metrópole limenhas, é preciso, portanto, buscar outros discursos e interpretações que partam do reconhecimento dessa nova realidade urbana, em toda sua especificidade, complexidade e dinamismo. Ou, como adverte Riofrío (2010b), é necessário "reinventar a cidade".

\section{Beatriz Silveira Castro Filgueiras}

Socióloga. Universidade Federal do Rio de Janeiro, Instituto de Pesquisa e Planejamento Urbano e Regional. Rio de Janeiro/RJ, Brasil.

beatrizfilg@yahoo.com.br

\section{Notas}

(*) Este artigo se baseia e sintetiza parte das discussões desenvolvidas na minha tese de doutorado em Sociologia, intitulada Imaginários do urbano, vínculos de urbanidade: a experiência contemporânea da heterogeneidade social na metrópole de Lima, Peru, e defendida em junho de 2013 no Instituto de Estudos Sociais e Políticos da Universidade do Estado do Rio de Janeiro.

(1) A segunda maior cidade do país na atualidade, Arequipa, concentra um contingente populacional onze vezes menor que aquele reunido em Lima Metropolitana.

(2) Sem considerar Lima Metropolitana, o Peru tem uma estrutura de cidades bastante equilibrada, prevalecendo, em $88 \%$ dos casos, os municípios de pequeno porte (entre 2 e 19.999 mil habitantes). Nos estratos superiores, no entanto, nunca existiu e não existe um número suficiente de cidades de grande e médio porte que possam equilibrar o desenvolvimento concentrado e desigual do país (Inei, 1996).

(3) Por primazia urbana entende-se a relação entre a capital e as três cidades seguintes em tamanho e importância. No caso peruano, Arequipa, Trujillo e Chimbote, respectivamente (Inei, ibid.). 
(4) No início dos anos 1980, um contexto de extrema instabilidade política e crise econômica deram lugar a um grave conflito interno no Peru. Os violentos embates entre o Partido Comunista del Peru - Sendero Luminoso (PCP-SL), o Movimiento Revolucionario Túpac Amaru (MRTA) e as Forças Armadas, sobretudo nas áreas rurais mais pobres do país, provocaram a fuga de milhares de pessoas e às vezes comunidades inteiras em direção às cidades da costa e à Lima em particular. Entre 1980 e 1992, num período em que as principais cidades da América Latina invertiam suas taxas de crescimento, o processo migratório em direção à capital peruana se transfigurava, com renovada intensidade e violência sem precedentes.

(5) Em português, tradução nossa: “Na prática, estas invasões fundavam novos polos ou núcleos de expansão urbana a partir dos quais são ocupados os terrenos adjacentes. Isto fazia com que as barriadas continuassem crescendo e, com o decorrer dos anos e à medida que foram sendo preenchidos os espaços entre o tecido urbano e as barriadas pioneiras, formaram o que agora são os cones da cidade. É também a partir deste período que podemos falar da cidade popular como um fenômeno transcendente e definidor para a urbe".

(6) Villa El Salvador foi o primeiro reassentamento urbano promovido pelo Estado peruano. Em abril de 1971, cerca de 200 famílias invadiram um terreno na localidade de Pamplona, ao sul de Lima; em poucos dias, quase 9 mil famílias já ocupavam o local. Dado o interesse do Estado na área tornada estratégica em função do crescimento urbano, do esgotamento das áreas disponíveis e da especulação do solo - houve tentativas de repressão violenta e expulsão dos invasores. Sem sucesso, iniciaram-se as negociações para o reassentamento das famílias em novo terreno designado pelo governo; um "grande bolsão" - um areal sem qualquer infraestrutura, plano de urbanização ou oferta de serviços - no qual o Estado pretendia alojar os invasores e todos aqueles que buscavam moradia nas barriadas que surgiam na capital (Riofrío, 1978). Duas semanas depois, em maio do mesmo ano, aproximadamente 7 das 9 mil famílias foram reassentadas. A criação de Villa El Salvador permitiria ao Estado, durante certo tempo, canalizar o crescimento no eixo sul de expansão da cidade.

(7) Não devemos generalizar esta afirmação para todas as barriadas e assentamentos populares em Lima, mas existem casos emblemáticos, como o de Villa El Salvador, que se tornou exemplo de mobilização comunitária e organização autogestionária com a criação da Comunidad Urbana Autogestionaria de Villa El Salvador (Cuaves) e a concepção de um plano de desenvolvimento e gestão urbana comunitários. A experiência inovadora, embora não isenta de conflitos e contradições, seria inclusive reconhecida internacionalmente.

(8) Ver mapa em anexo, "Distribuição dos distritos de Lima Metropolitana por zonas".

(9) A expressão cholo(a) faz referência à presença e adaptação, no contexto urbano, da população de origem andina e campesina. Embora o termo carregue forte carga pejorativa, serviria também à reafirmação cultural e identitária da população migrante na cidade consagrado, por exemplo, em um verso clássico do cancioneiro popular-urbano na segunda metade do século XX, "cholo soy y no me compadezcas". 
(10) De modo a evitar ambiguidades, é preciso esclarecer o recorte territorial que adotamos aqui ao referirmos à "metrópole de Lima", sobre a qual nem no contexto local existe consenso. As definições de "Lima" são muitas, sobrepostas e contraditórias, evocando escalas e territórios distintos que abarcam de maneira ambígua seu território metropolitano. No que tange à organização político-administrativa do território, Lima Metropolitana - ou a Província de Lima - abrange 43 distritos, sendo sua capital o Distrito de Lima (ou Cercado de Lima); distrito que, por sua vez, além de referir-se atualmente ao centro histórico da metrópole, é também a capital política e administrativa do país. Mas essa definição, embora "oficial”, não é consensual e o próprio Inei (Instituto Nacional de Estadística e Informática) adota uma formulação distinta que inclui a Província Constitucional de Callao. Callao, apesar de totalmente integrada à malha urbana conurbada da metrópole limenha - constituindo inclusive um dos seus vetores mais estratégicos, estando aí o porto e o aeroporto mais importantes do país - é uma entidade territorial, política e administrativa autônoma que elege seus próprios governantes (provinciais e regionais) e que não participa, portanto, das decisões que envolvem o conjunto da metrópole e/ou sua administração - inclusive, muitas vezes, dificultando-as. Embora seja necessário reconhecer que, considerando este território conurbado e suas conexões dinâmicas, Callao é parte fundamental das dinâmicas metropolitanas de Lima, convencionamos aqui o uso da definição político-administrativa de Lima Metropolitana, composta por 43 distritos cuja organização social e territorial distingue, na metrópole, quatro regiões - Lima Centro, Lima Norte, Lima Leste e Lima Sul -, e cuja população era estimada, em 2012, em quase 8,5 milhões de habitantes (Fonte: "Lima tendría 8 millones 432 mil habitantes en la actualidad, informa Inei", La República, 18 de janeiro de 2012, versão eletrônica: http://www.larepublica.pe/18-012012/lima-tendria-8-millones-432-mil-habitantes-en-la-actualidad, acesso em 13/11/2012). Ver mapa em anexo.

(11) No início da década de 1990, Alberto Fujimori seria eleito presidente, num contexto de aguda crise inflacionária, paralisia estatal e da crescente ameaça subversiva. Em 5 de abril de 1992, Fujimori declarava o autogolpe de Estado, instituindo uma ditadura que duraria quase uma década. Devida à forte pressão internacional (que incluía o bloqueio de empréstimos financeiros ao país), em 1995 Fujimori reinstituiu o processo democrático, reabriu o Congresso e convocou novas eleições. Legitimado pela relativa estabilidade econômica e, sobretudo, pela derrota da insurgência subversiva, foi reeleito. Contudo, analistas ressaltam o caráter de "fachada" desse processo e a continuidade do projeto político autoritário, até a queda do regime com a fuga de Fujimori do país e sua renúncia, via fax, nos anos 2000 (Burt, 2009).

(12) Devido ao excessivo centralismo peruano, a maior parte destes novos investimentos tenderá a se concentrar quase que exclusivamente em Lima. Com exceção dos grandes projetos de mineração, hidrelétricas e petróleo - que afetam de modo especial as comunidades rurais e indígenas tanto na região andina como amazônica e são, hoje, os principais responsáveis pela deflagração de conflitos sociais no Peru -, todos os setores mais dinâmicos e "modernos" da economia atuam apenas e/ou principalmente na capital. O que não equivale dizer, contudo, que aqueles setores não tenham forte impacto na cena metropolitana, uma vez que têm a capital como seu centro financeiro, administrativo e operacional; principal lugar de residência e estadia das altas classes executivas que demandam serviços e estrutura especializados, além de ser também aí onde são tomadas todas as decisões de governo acerca dos investimentos e da política de desenvolvimento nacional. 
(13) Projetos de valorização crescentemente incluem também o patrimônio arqueológico que, apesar dos séculos de destruição contínua, continua a imprimir suas marcas na paisagem limenha. Em Lima Metropolitana, existem hoje 217 sítios arqueológicos identificados pelo Ministério da Cultura; incluída a Província de Callao, são mais de 350. No entanto, a grande maioria permanece em estado de abandono e sofre com as pressões do crescimento urbano e da especulação imobiliária. Poucas delas estão habilitadas para visitação - com destaque para o Santuário de Pachacámac (distrito de Lurín), a Huaca Pucllana (distrito de Miraflores) e o complexo circunscrito pelo Parque de las Leyendas (distrito de San Miguel). (Fonte: Perú - Ministerio de la Cultura, disponível em http://www.mcultura.gob.pe/principales-sitiosarqueologicos-de-lima, acesso em 4/3/2013).

(14) Nesse cenário, o Cone Norte - em particular, os distritos de Los Olivos, Comas e Independencia - tem cumprido um papel de destaque e, em função do crescimento pujante do qual foi objeto nas últimas duas décadas, se transformou no exemplo mais paradigmático do novo dinamismo econômico das áreas de urbanização popular em Lima.

(15) Para citar um exemplo, a instalação do shopping Mega Plaza Norte, no distrito de Independencia em 2002, implicou a quebra e/ou o desaparecimento de mais de 1.500 estabelecimentos comerciais locais (pequenas lojas e bodegas), gerando apenas 800 postos de trabalho ocupados, via de regra, por moradores de outras regiões da cidade.

(16) Em português, tradução nossa: “Me considero limenho, pois nasci em Lima, mas meus pais nasceram na província e, portanto, seus pais também, o que me torna também parte da província de onde vieram, mas também me torna limenho legalmente falando, porque a certidão de nascimento explica o meu lugar de nascimento, em conclusão sou limenho e, ao mesmo tempo, sou provinciano".

\section{Referências}

ARROYO, R. e ROMERO, A. (2008). “Lima Metropolitana y la globalización: plataforma de integración subordinada o espacio de autodeterminación en América Latina”. In: CÓRCOVA MONTÚFAR, M. (coord.). Lo urbano en su complejidad: una lectura desde América Latina. Quito, Flacso/Ministerio de Cultura de Ecuador.

ÁVILA MOLERO, J. (2001). Globalización, identidad, ciudadanía, migración y rituales andinos des/ localizados: el culto al Señor de Qoyllur Rittien Cusco y Lima. Disponível em: http://bibliotecavirtual. clacso.org.ar/ar/libros/becas/2000/avila.pdf. Acesso em: 3 set 2013.

BARREDA, J. e RAMÍREZ CORZO, D. (2004). "Lima: consolidación y expansión de una ciudad popular”. In: ARAMBuru, C. E. et al. Perú Hoy - Las ciudades en el Perú. Lima, Desco.

BURT, J-M. (2009). Violencia y autoritarismo en el Perú: bajo la sombra de Sendero y la dictadura de Fujimori. Lima, IEP/SER.

CABRERA, T. (2009). "El espacio público en la ciudad popular”. In: CALDERÓN COCKBURN, J. (org.). Los nuevos rostros de la ciudad de Lima: Foro Urbano. Lima, Colegio de Sociólogos del Perú. 
CABRERA, T. e VILLASECA, M. (2007). Presentes, pero invisibles: mujeres y espacio público en Lima Sur. Lima, Desco - Programa Urbano.

CÁNEPA, G. (2007). Geopoética de identidad y lo cholo en el Perú: migración, geografía y mestizaje. Revista Crónicas Urbanas. Lima, n. 12, pp. 29-42.

CHION, M. (2009). "Dimensión metropolitana de la globalización: Lima a fines del siglo XX”. In: VEGA CENTENO, P. (ed.). Lima, diversidad y fragmentación de una metrópoli emergente. Quito, Olacchi.

DEGREGORI, C. I.; BLONDET, C. e LYNCH, N. (1986). Conquistadores de un nuevo mundo: de invasores a ciudadanos en San Martín de Porres. Lima, IEP.

DOMINGUES, J. M. e MANEIRO, M. (2004). Revisitando Germani: a interpretação da modernidade e a teoria da ação. Dados - Revista de Ciências Sociais. Rio de Janeiro, v. 47, n. 4, pp. 643-668.

FILGUEIRAS, B. S. C. (2008). Metrópoles em crise: vida urbana na América Latina contemporânea e a problemática dos vínculos sociais. Cadernos Ippur/UFRJ. Rio de Janeiro, v. XXII, n. 1, pp. 173-192.

FONTES, P. (2008). Um Nordeste em São Paulo: trabalhadores migrantes em São Miguel Paulista (1945-66). Rio de Janeiro, FGV.

FRANCO, C. (1989). Informales: nuevos rostros en la vieja Lima. Lima, Cedep. (1991). Imágenes de la sociedad peruana: la otra modernidad. Lima, Cedep.

GERMANI, G. (1965). Política y Sociedad en una Época de Transición: de la sociedad tradicional a la sociedad masas. Buenos Aires, Editorial Paidós.

GOLTE, J. e ADAMS, N. (1987). Los caballos de Troya de los invasores: estrategias campesinas en la conquista de la gran Lima. Lima, IEP.

GORELIK, A. (2004). Miradas sobre Buenos Aires: historia cultural y crítica urbana. Buenos Aires, Siglo XXI.

(2005). A produção da "cidade latino-americana". Tempo Social-Revista de Sociologia da USP. São Paulo, v. 17, n. 1, pp. 111-133.

INEI - Instituto Nacional de Estadística e Informática (1996). Dimensiones y características del crecimiento urbano en el Perú: 1961-1993. Lima, Inei/UNFPA.

JACINTO PAZOS, P. (2007). Modernidad, identidad y representaciones limeñas. Los microempresarios frente a los megamercados. SCIENTIA - Revista del Centro de Investigación de la Universidad Ricardo Palma. Lima, v. IX, n. 9, pp. 59-90.

JOSEPH, A. J. (1999). Lima megaciudad: democracia, desarrollo y descentralización en sectores populares. Lima, Alternativa/Unrisd.

JOSEPH, A. J.; CASTELLANOS, T.; PEREYRA, O. e ALIAGA, L. (2005). "Lima, 'Jardín de los senderos que se bifurcan': segregación e integración”. In: GRIMSON, A.; PORTES, A. e ROBERTS, B. (eds.). Ciudades latinoamericanas: un análisis comparativo en el umbral del nuevo siglo. Buenos Aires, Prometeo Libros.

KAZTMAN, R. e RIBEIRO, L. C. de Q. (2008). Metrópoles e sociabilidade: os impactos das transformações socioterritoriais das grandes cidades na coesão social dos países da América Latina. Cadernos Metrópole. São Paulo, n. 20, pp. 241-261.

LATOUCHE, S. (1996). A ocidentalização do mundo: ensaio sobre a significação, o alcance e os limites da uniformização planetária. Petrópolis, Vozes. 
LEFÈBVRE, H. (1999). A revolução urbana. Belo Horizonte, Ed. UFMG.

LUDEÑA URQUIZO, W. (2009). "Lima de los noventa: neoliberalismo, arquitectura y urbanismo". In: VEGA CENTENO, P. (ed.). Lima, diversidad y fragmentación de una metrópoli emergente. Quito, Olacchi.

MARTÍN-BARBERO, J. (1991). Dinámicas urbanas de la cultura. Disponível em: http://www.naya.org. ar/articulos/jmb.htm. Acesso em: 3 set 2013.

(2001). Al sur de la modernidad: comunicación, globalización y multiculturalidad. Pittsburgh, Instituto Internacional de Literatura Iberoamericana - Universidad de Pittsburgh.

MATOS MAR, J. (2004). Desborde popular y crisis del Estado. Veinte años después. Lima, Fondo Editorial del Congreso del Perú.

MONTOYA URIARTE, U. (2002). Entre fronteras: convivencia multicultural, Lima siglo XX. Lima, Concytec/Sur - Casa de Estudios del Socialismo.

NUGENT, D. (2007). “Estado y nación vistos desde los márgenes: la reconfiguración del campo moral en el Perú del siglo XX". In: LAGOS, M. L. e CALLA, P. (orgs.). Antropología del Estado: dominación y prácticas contestatarias en América Latina. La Paz, INDH; PNUD.

ORTEGA, J. (1986). Cultura y modernización en la Lima del 900. Lima, Cedep.

PORTES, A.; ROBERTS, B. R. (2005). “La ciudad bajo el libre mercado: la urbanización en América Latina durante los años del experimento neoliberal”. In: GRIMSON, A.; PORTES, A. e ROBERTS, B. (eds.). Ciudades latinoamericanas: un análisis comparativo en el umbral del nuevo siglo. Buenos Aires, Prometeo Libros.

PREVÔT SCHAPIRA, M.-F. (2001). Fragmentación espacial y social: conceptos y realidades. Perfiles Latinoamericanos - Revista de la Sede Académica de México de la Facultad Latinoamericana de Ciencias Sociales. Ciudad de México, año 9, n. 19, pp. 33-56.

QUIJANO, A. (1980). Dominación y cultura. Lo cholo y el conflicto cultural en el Perú. Lima, Mosca Azul.

RIBEIRO, A. C. T. (2004). Oriente negado: cultura, mercado e lugar. Cadernos PPG-AU. Salvador, ano 2, pp. 97-107.

(2009). "Presentificação, impulsos globais e espaço urbano. O novo economicismo". In: POGLIESE, H. e EGLER,T. T. C. (comp.). Otro desarrollo urbano: ciudad incluyente, justicia social y gestión democrática. Buenos Aires, Clacso.

RIOFRÍO, G. (1978). Se busca terreno para próxima barriada: espacios disponibles en Lima 1940-19781990. Lima, Desco.

(2004). "Pobreza y desarrollo urbano en el Perú". In: ARAMBURU, C. E. et al. Perú Hoy - Las ciudades en el Perú. Lima, Desco.

(2009). “Imágenes y perspectivas del crecimiento urbano de Lima”. In: CALDERÓN COCKBURN, J. (org.). Los nuevos rostros de la ciudad de Lima: Foro Urbano. Lima, Colegio de Sociólogos del Perú.

(2010a). Alan García, alcalde de Lima. Perú Hoy - Desarrollo, democracia y otras fantasías. Lima, Desco.

(2010b). Reinventar la ciudad. Revista Quehacer. Lima, n. 179, pp. 22-27. 
RÍOS BURGA, J. R. (2006). Sociología de Lima - Las microculturas en el Centro Histórico: individuación, socialización, identidad, vida cotidiana e intimidades. Lima, Fondo Editorial de la Facultad de Ciencias Sociales.

RODRÍGUEZ ROBLES, M. E. (1997). “Migración y violencia: jóvenes ayacuchanos y huancavelicanos en la ciudad de Lima”. In: BALBI, C. R. (ed.). Lima: aspiraciones, reconocimiento y ciudadanía en los noventa. Lima, PUCP.

ROMERO, J. L. (2004). América Latina: as cidades e as ideias. Rio de Janeiro, Editora UFRJ.

ROMERO REYES, A. (2004). La economía urbana de Lima Metropolitana: los procesos y retos de desarrollo. Cuadernos de Desarrollo Económico Local: lecturas de la economía del norte de la ciudad. Lima, Alternativa, pp. 25-52.

SACHAEDEL, R. (1982). De la homogenización a la heterogenización. Apuntes - Revista de Ciencias Sociales. Lima, n. 12, pp. 3-17.

SANTOS, M. (2005). Da totalidade ao lugar. São Paulo, Edusp.

VEGA CENTENO, P. (2009). “Introducción”. In: VEGACENTENO, P. (ed.). Lima, diversidad y fragmentación de una metrópoli emergente. Quito, Olacchi. 


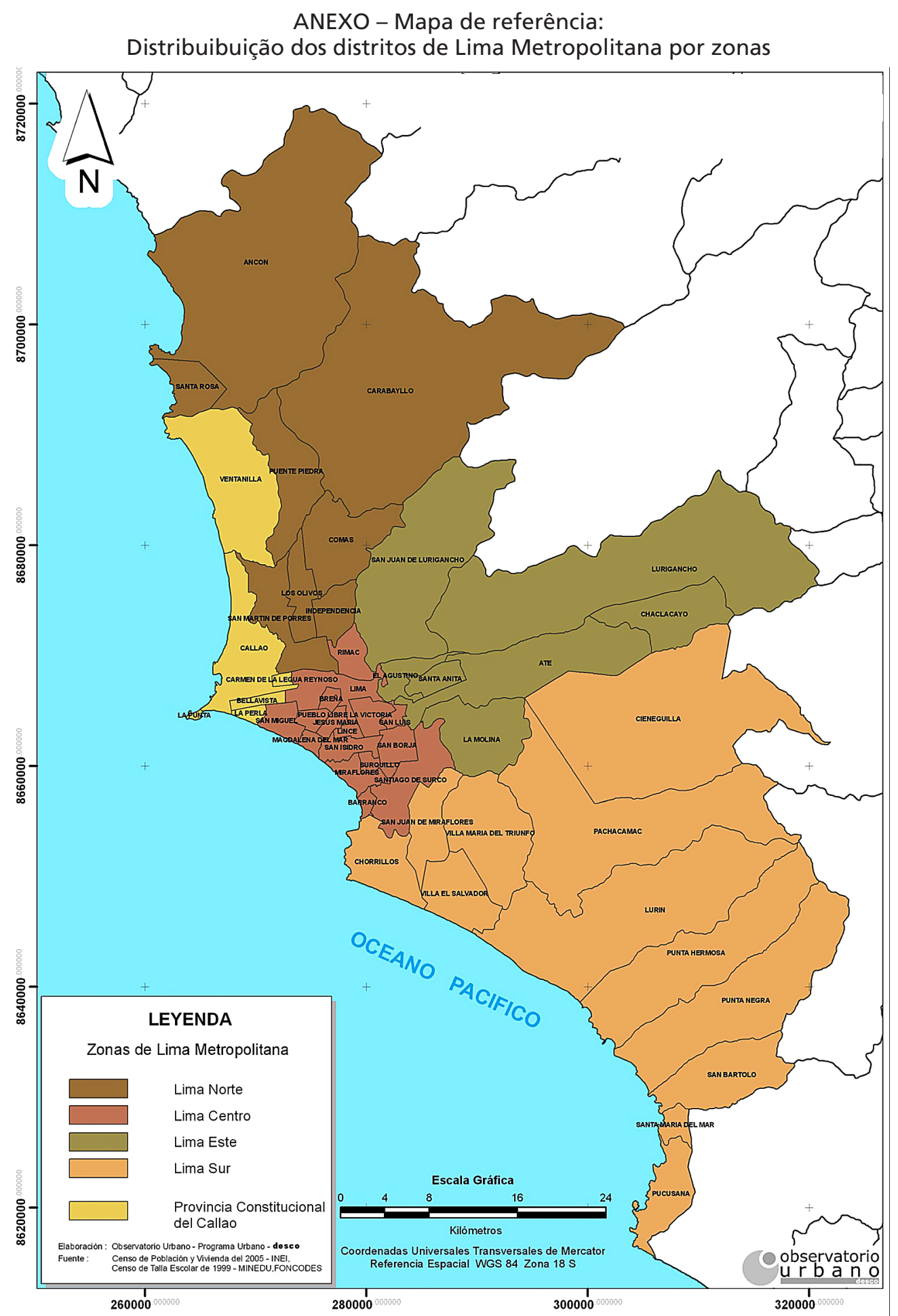

Fonte/elaboração: Desco,Observatório Urbano - Programa Urbano,s/d. Disponível em: http://www.urbano.org.pe/downloads/ observatorio_urbano/Zonas\%20de\%20Lima\%20Metropolitana jpg. Acesso em: 12 abr 2013. 